\title{
Incidental English Vocabulary Acquisition Through Reading: A Review in the Last Two Decades
}

\author{
Fangfang Zou ${ }^{1} \&$ Xiaoqin Yan ${ }^{1}$ \\ ${ }^{1}$ Foreign Languages College, Jiangxi Normal University, Jiangxi, China \\ Correspondence: Fangfang Zou, Foreign Languages College, Jiangxi Normal University (JXNU), Nanchang, \\ Jiangxi, China.
}

Received: October 17, 2019

Accepted: November 10, 2019 Online Published: November 12, 2019

doi: $10.5539 /$ elt.v12n12p39

URL: https://doi.org/10.5539/elt.v12n12p39

\begin{abstract}
This article reviews the empirical research on incidental vocabulary acquisition in English reading in the latest twenty years from three aspects: its comparison with intentional vocabulary acquisition, its affecting factors and previous studies of its problems. Teaching implications have also been provided.
\end{abstract}

Keywords: incidental vocabulary acquisition, English reading, retention

\section{Introduction}

Substantial research has demonstrated that the majority of new words in one's first language can be acquired incidentally through listening and reading. Concerning vocabulary growth, Nagy, Anderson and Herman (1987: 261) claimed that during normal reading, the incidental acquisition of vocabulary meaning does occur. Later, Krashen (1989) extended this belief to second language acquisition. Laufer (2003) argued that a large part of vocabulary is learned incidentally.

Incidental vocabulary acquisition is defined that learners gain the new words without the intent but as a by-product of listening or reading (Laufer, 2003). The research orientation of incidental vocabulary acquisition varies greatly, from being neglected to being noticed to being stressed. More and more studies are conducted to compare the intentional and incidental vocabulary acquisition; for instance, which learning mode is a better way to gain new words; to explore what factors and how these factors affect the amount of vocabulary acquired and to investigate the problems brought by the incidental vocabulary learning--retention problems. These studies will be detailed as below.

\section{The Comparison Between Intentional Vocabulary Acquisition and Incidental Vocabulary Acquisition}

Though researches have shown that incidental vocabulary acquisition can enhance a significant proportion of L2 vocabulary learning, the intentional mode of learning new words is still the main source of L2 vocabulary growth (Bordag et al., 2017). In terms of definition, incidental learning deemed the learning as a byproduct of learning something else; on the contrary, intentional learning is the learning that planned by students or teachers. What matters most is their different effectiveness in words gains.

Despite the disadvantageous situation of incidental learning towards acquiring new words, it is believed that incidental vocabulary acquisition is sometimes advantageous over explicit instruction (Kweon \& Kim, 2008). The reason is, firstly, that reading and word learning can happen at the same time. And contextualized input leads to a richer sense of a word. Lastly, the incidental vocabulary acquisition enables learners to acquire word meanings, words collocations and colligations that are not easily learned by L2 learners. However, Peters et al. (2009) have made a direct comparison in his research and argued that incidental vocabulary acquisition is less effective than intentional vocabulary learning, usually leading to less and slower gains and even worse retention. The reason lies in that a plan to learn the new words can facilitate vocabulary acquisition by making leaners perceive the words as something important and then drawing learner's attention to the meaning and form. A research by Vidal (2011) concluded that learners achieved higher incidental vocabulary gains when the words were explicitly elaborated compared with those implicitly elaborated ones because the formal characteristic of explicit elaborations clearly draws readers 'attention to the understanding and retention of the given words. Sun (2017) also argued that explicit vocabulary instruction that underlies the lexical items leads to initial word learning more effectively. 
The combination of intentional and incidental learning can generate higher word gains than either of those two types of learning mode. Guo (2010) studied the effect of incidental learning and intentional learning on vocabulary acquisition of ESL students of different levels in Chinese universities. Ninety-three students were assigned to two groups by using texts with 26 target words, vocabulary exercises for experimental group and vocabulary and writing test for all the participants. The study showed that both incidental learning and intentional learning result in significant gains in learners' vocabulary knowledge, but the combination of the incidental and intentional learning instruction achieves greater vocabulary gains and better retention.

Explicit learning can yield better results in the aspect of vocabulary growth; but incidental learning plays an incomparable role in vocabulary acquisition and should not be neglected. Many techniques can be adopted to effectively employ the incidental learning.

\section{The Factors Affecting Incidental L2 Vocabulary Acquisition}

How to ensure its effectiveness of incidental vocabulary acquisition to enlarge learners' English vocabulary gains unpurposefully should be taken into serious consideration. Plenty of researchers have made great contributions to bring force the full strength of incidental vocabulary acquisition-- predictability of word meanings, types of words, synonym generation, the use of glossing, the repetition of target words, vocabulary knowledge, reading strategies or materials etc. All have been proven to exert a great influence on the efficiency of incidental vocabulary acquisition.

The discovery and usage of affixes facilitate the inference of the word meaning and word learning. Vidal (2003) once pointed out that it tends to be easier to acquire the words whose meaning can be inferred by breaking them into parts. Schmitt and Zimmerman (2002) claimed that learners tend to learn more new words if the derivative forms of the words are paid attention to. As for the incidental vocabulary acquisition, predictability of form-based word meanings is conducive to vocabulary gains. For example, Vidal (2011) found that predictability from word form and parts contributes to acquisition through reading. Vocabulary learning of 230 first-year undergraduates was studied from four aspects: frequency of occurrence, type of word and elaboration, and predictability from word form and parts. The results revealed that learners tend to gain more vocabulary through reading when words are similar to $\mathrm{L} 1$ and morphologically predictable.

The words can be divided into different types according to different standards. Nation (2001) classified words as high-frequency, academic, technical and low-frequency words based on the criteria of frequency of use. A previous study of his revealed that different types of words affect the vocabulary gains in a different way; it's easier for students to acquire words for technical texts than for academic and low-frequency ones. Vidal (2011) found that academic words are slightly conducive to incidental vocabulary gains. Besides, among technical, low-frequency and academic words, readers had the least vocabulary gains for academic words because this type of words may not be perceived by readers as relevant to the understanding of the reading texts. In terms of word class, words can be further sorted into nouns, verbs, etc. Kweon and Kim (2008) adopted the authentic literary texts to investigate the number of word acquired incidentally by selecting verbs, nouns, and adjectives as three groups of L2 Korean learners of English. Results suggested that nouns are easier to learn than other two word classes.

As Barcroft (2009) pointed out, synonym generation exerts a negative influence on incidental L2 vocabulary learning. He studied 114 Spanish-speaking learners of L2 English at low- and high-intermediate proficiency levels who were instructed to read a text with 10 target English words with their Spanish translations in parentheses after each target word for comprehension under four conditions: the incidental, intentional, incidental-semantic and intentional-semantic condition. Spanish-to-English and English-to-Spanish cued recall tasks were administered to measure productive and receptively oriented vocabulary. He found that semantically oriented task (synonym generation) negatively affected L2 word-form learning during reading, regardless of intentional or incidental learning or on the proficiency level of the learners (low intermediate versus high intermediate).

As Ellis (2002) claimed, high exposure frequency affects vocabulary acquisition. Vidal (2011) argued that frequency of word occurrence best predicted vocabulary acquisition in the reading model which facilitates readers to remember the word. Tekmen and Daloğlu (2006) explored the relationship between vocabulary acquisition and frequency of occurrence among three groups of students of intermediate-level, upper-intermediate, and advanced students. The Vocabulary Levels Test as the pre-test and two post-tests of 30 of 60 words were selected form the given text in terms of frequency level in the text. The results showed that if a word appeared in the text more frequently, more learners were able to gain it. Additionally, Kweon and Kim (2008) adopted the authentic literary texts to explore the relationship between the frequency of occurrence and 
the learning rates of words by selecting verbs, nouns, and adjectives based on their frequencies. It turned out that higher frequency words were more likely to be learned and were less likely to be attritted. Chen and Truscott (2010) also argued that increasing encounters do help gain vocabulary, especially, with different patterns of development on knowledge of orthography, part of speech, and meaning. However, semantic knowledge and orthographic knowledge of difficult words do not increase with repeated exposures. The better word gain is seemingly related with the number of exposures. In his case study to investigate how word exposures affect the acquisition of different aspects of vocabulary knowledge, Hu (2013) recruited a well-motivated learner with great interest in learning English, and found that repetition make a most difference to orthographical knowledge of vocabulary. Bisson et al. (2014) have also explored the relationship between the number of exposures and incidental words-learning. The number of exposures to FL words in an incidental learning phase varied between 2, 4, 6 and 8 exposures. The results revealed that repeated exposures proved to make a difference to vocabulary gains during the first few exposures; thereafter, the gains seemed to decrease. Reynolds(2016),in a study to investigate what properties of target words can best enhance incidental vocabulary acquisition, concluded that frequency contributed to meaning recall mostly, followed by cognateness. The length of words and lexicalization showed little impact in his study.

Researchers tend to investigate the relationship between exposure frequencies with incidental vocabulary acquisition by means of eye-tracking. Mohamed (2018), for example, combined extensive reading studies and eye-movement research in his study of advanced second language learners of English, recommending that maximizing exposure to words is the best conditions for acquiring new vocabulary. Godfroid (2018) in his study confirmed that repetition of target words contribute to the gain of all three types of vocabulary knowledge: form recognition, meaning recall and meaning recognition. Among them, exposure tops influence on form recognition.

Malone (2018) explored the roles of exposure frequency, aural enhancement (AE) of input and individual differences in working memory (WM) during L2 incidental vocabulary learning in reading among 80 intermediate-level ESL learners from two U.S. university Intensive English Programs. To measure the vocabulary learning, a simple form-recognition task and a multiple-choice form-meaning connection test were adopted. Three WM tests were also administered, with English writing proficiency as a covariate through a cloze measure. The results showed that controlling for duration of exposures, measurable word gains occurred at the two-exposure level for new words both in form recognition and form-meaning connections.

Glossing is one of the numerous vocabulary enhancement techniques to increase the effectiveness of incidental vocabulary learning while reading. It is widely adopted in various teaching and learning materials. In the light of the positive effectiveness of gloss, researchers have shifted their focus from gloss effects to the nature of gloss of different types. In a survey of learning new L2 words from reading, Laufer (2001) reported that reading with word-focused tasks lead to better results in incidental vocabulary acquisition. To find out how different reading tasks such as reading with marginal glosses, reading with marginal glosses plus making sentences with target words, reading with dictionary at one's disposal and reading with no external aid affect the incidental vocabulary acquisition and its retention, $\mathrm{Xu}$ (2010) studied $125 \mathrm{ESL}$ freshmen through a reading passage which contains 10 target words selected from CET-4 training book. The results showed that among four different tasks, no provision of external aid shows the least efficiency in learners' IVA gains and the marginal glosses is the most beneficial.

Higher-level language learners tend master larger size of lexical knowledge (Lewis, 2000). Then researchers began to explore whether this lexical language is conducive to enlarge incidental vocabulary acquisition. In a study on the relationship between vocabulary acquisition and L2 proficiency, Tekmen and Daloğlu (2006) found that the advanced-level students achieved a positively greater number of words through reading than the intermediate-level and upper intermediate-level students. Lee and Pulido (2017) stratified participants' English proficiency level into three groups: high, intermediate and low based on the results of the National Academic Achievement Test of English. They believed that learners' L2 reading proficiency can significantly predict the vocabulary gain with higher proficiency resulting in more gains in his research in which participants' English proficiency level ranging from high to intermediate to low based on the results of the National Academic Achievement Test of English.

The implication of one's L1 lexicalization towards incidental word learning has received limited attention. However, it can pose a profound significance for learner's vocabulary gains. Chen and Truscott (2010) has done a research involved with ten target words of which five words are lexicalized in the participants' L1- Mandarin. These words were presented in L2 reading passages. They found that L2 words not lexicalized in learners' L1 will cause learning difficulty; and thus lower incidental vocabulary acquisition, both immediately and after a 
two-week delay.

Previous literature displayed that students' motivation facilitates their incidental vocabulary learning, as even the best materials are little good if students do not get themselves involved in learning (Schmitt, 2008). In order to explore the relationship between motivation and incidental acquisition of second language vocabulary, Ajidah et al. (2013) asked two classes of junior students to do a reading-while-reading task on an extract from Giant Steps, with results indicating that motivational involvement makes a difference in activating L2 vocabulary in short-term acquisition, however, not in long-term. Papi (2018) conducted an experimental study to compare English learners' vocabulary learning outcomes on 189 ESL learners in a large US university of two motivational orientations: promotion and prevention under the gain framed and loss framed conditions through the regulatory focus questionnaire, reading comprehension tests and L2 vocabulary tests. The study highlights that motivational effects regulate the task-based learning process at different levels including the regulatory focus of the learners and the task; thus, learners are engaged in the task and show better performance in learning the meanings of vocabulary.

When guessing the meaning of new words, learners are always told to get the meaning based on the context before and after. Zahar (2001) found out that no relationship exist between gaining words and the types of contexts in English reading in his study of 144 high school boys in Montreal who receive 75 hours of ESL lesson an academic year following a pre-test-post-test experimental model. In a study of 50 Japanese EFL learners, Webb (2008), however, concluded that the quality of the context may have a greater impact on gaining the meaning of the words compared with the number of encounters with target words. The results revealed that context has a positive effect on gaining knowledge of meaning but little effect on gaining knowledge of form. Hu (2013) also concluded that context richness is more helpful for form-meaning connection and grammatical functions more among various aspects of world knowledge.

Higher vocabulary acquisition requires learner's higher involvement. In a meta-analytic study of twelve separate studies, Huang, Eslami and Willson (2012) stated that the higher degree of involvement load a learner is carrying when performing a reading task, the more vocabulary the learner tends to gain. After being filtered by a series of criteria, six published and six unpublished articles were selected, each of which was reviewed and coded for information required to calculate effect sizes and information related to the five mediator variables including design quality, output tasks types, time on task, genres of text, and text-target word ratios. The statistics displayed the following results. Firstly, an output task while reading is helpful to enhance vocabulary gains. Secondly, time-on-task length was positively correlated with incidental vocabulary learning. Thirdly, combination of expository and narrative texts leads to more vocabulary gains than either an expository or a narrative text. Moreover, learners who read expository text outperformed those read narrative texts. Through an eye-tracker recording participants' eye movements to measure the role of attention in incidental L2 vocabulary acquisition, Godfroid et al. (2013) believed that amount of attention directly and positively affect amount of gained vocabulary. As for the quantitative involvement, Pellicer (2015) concluded that longer reading times result in better recall the meanings of words. Godfroid (2018) also argued that summed total reading time play a significant role in the learning of word learning in his study investigating how learners acquire multifaceted vocabulary knowledge incidentally through reading a long, authentic text.

The topic of the reading passage makes a difference to the incidental vocabulary acquisition. Topic familiarity and rhetorical organization facilitates comprehension on reading materials. Pulido (2007) deemed that the greater vocabulary is gained when the greater level of passage comprehension is contributed; namely, text comprehension is conducive to L2 vocabulary learning incidentally. Therefore, topic familiarity and rhetorical organization are helpful to incidental vocabulary acquisition. Mahdavy (2011) investigated 64 intermediate EFL learners who read four different narratives in terms of topic familiarity and rhetorical organization through preliminary English test, vocabulary pre-test, two different narratives with altered rhetorical organization and vocabulary post-test. Finally, the results suggested that familiarity with the text content and text organization are related to the incidental acquisition of new vocabulary. Moreover, in the combined effects condition of familiar content and well-organized text, the proportion of incidental vocabulary learning was the highest. With regard to the topic interest, in their eight-week study with participants from seven intact ninth-grade classes, Lee and Pulido (2017) supported that topic interest associates with incidental vocabulary acquisition with higher interesting topic leading to higher vocabulary growth.

\section{Previous Studies of Problems brought by Incidental Vocabulary Acquisition}

Plenty of ways are testified to help learners gain better vocabulary acquisition incidentally in reading. However, learners learn the words in long term rather than for a certain time. Therefore, more and more researchers have 
come to explore the problem on incidental vocabulary retention. For example, in a study to compare what effect the three annotation types including text-only, picture-only, and a combination of the two have on L2 incidental vocabulary retention, Yoshii and Flaitz (2002) recruited 151 adult ESL learners to read a story for comprehension purpose on the internet in terms of three kinds of retention assessment including picture recognition, word recognition and definition supply tests. The results showed that the retention rate of incidental vocabulary among three groups did not show much difference in terms of picture recognition, word recognition and definition supply tests. In addition, in their study of 12 Korean learners of English, Kweon and Kim (2008) adopted the authentic literary texts to work out what proportion of the incidentally learned words are retained one month later by comparing the results of two post-tests conducted between months. They concluded that most acquired words were retained without much attrition. Furthermore, Xu (2010) argued that, as for the retention of IVA gains, all groups in her research have lost some in the long run; however, the four groups were no longer significantly different from each other. Chen and Truscott (2010) also argued that increasing exposures help with incidental vocabulary gains and the effects remains for only two weeks. What's more, Vidal (2011) revealed that word gains seem to leave more durable traces with listening input than that with reading input especially for high-proficiency learners. Reading also resulted in greater retention one month after the input, except for the highest proficiency students. Lee and Pulido (2017) also confirmed that vocabulary growth increased from the passage with interesting topic tends to last over time. In a study to explore how initial test interval and feedback timing affect vocabulary retention in L2 English reading, Lin (2018) carried out a research with participants coming from different majors while controlling the retention interval. The results revealed that combination of a short study-test lag and delayed feedback lead to better word retention and delayed feedback is better than immediate feedback with respect to vocabulary retention.

\section{Conclusion}

The review of studies in past two decades has some interesting pedagogic implications. It is concluded that although learners can gain new words incidentally, intentional learning yields higher vocabulary acquisition. The factors that can enhance incidental L2 vocabulary acquisition include three aspects: the word itself, the reading text and the learners. The word itself mainly covers the predictability of word meanings, the certain word types such as high-frequency words, the certain word class such as nouns, a certain number of exposures of the word and the glossing of the word especially the MI and marginal glosses. As for the reading text, the high-quality and richness of the context, topic familiarity and rhetorical organization matter a lot. In terms of the learner factors, learner's high proficiency level, high motivation, high involvement and L1 lexicalization are all helpful to gain new words. Factors disadvantageous of vocabulary acquisition lie on synonym generation of the word.

The implications for English teachers to facilitate L2 vocabulary acquisition are as follows. Firstly, during the process of learning new words, it is more effective for teachers to combine both implicit and explicit instructions on the target words. Secondly, teaching knowledge of word formation and certain attention to low-frequency words are very helpful. Thirdly, teachers may create opportunities for students with enough exposures to the words. Additionally, teachers can employ sorts of activities to bring students' attention to target words, and in this way, the reading times and involvement can also be enlarged. Moreover, it is better for students to be dealing with materials with topics of interest and relevant experiences to their daily life. Teachers could also make an effort to integrate vocabulary goals with various contexts. For example, they can consider adopting rewarding policy to motivate students to learning more. Lastly, teachers can plan tests and review the answers in the next class to promote students' retention of target words.

\section{References}

Ajideh, P., Rahimpour, M., Amini, D., \& Farrokhi, F. (2013). Motivational strategies, task Effectiveness and incidental acquisition of second language vocabulary. Journal of Language Teaching and Research, 4(5), 1044-1052. https://doi.org/ 10.4304/jltr.4.5.1044-1052

Barcroft, J. (2009). Effects of Synonym Generation on Incidental and Intentional L2 Vocabulary Learning During Reading. TESOL Quarterly, 43(1), 79-103. https://doi.org/10.1002/j.1545-7249.2009.tb00228.x

Bisson, M. J., Walter. J. B. van Heuven., Conklin, K., \& Tunney, R. J. (2014). The role of repeated exposure to multimodal input in incidental acquisition of foreign language vocabulary. Language Learning, 64(4), 855-877. https://doi.org/10.1111/lang.12085

Bordag, D., Kirschenbaum, A., Rogahn, M., \& Tschirner, E. (2017). The role of orthotactic probability in incidental and intentional vocabulary acquisition L1 and L2. Second Language Research, 33, 147-178. https:// doi. org/10.1177/0267658316665879 
Chen, C., \& Truscott, J. (2010). The effects of repetition and L1lexicalization on incidental vocabulary acquisition. Applied Linguistics, 31(5), 639-713. https://doi.org/10.1093/applin/amq031

Ellis, N. (2002). Frequency effects in language processing: A review with implications for theories of implicit and explicit language acquisition. Studies in Second Language Acquisition, 24, 143-188. https://doi.org/10.1017/S0272263102002024

Godfroid, A., Boers, F., \& Housen, A. (2013). An eye for words: Gauging the role of attention in incidental L2 vocabulary acquisition by means of eye-tracking. Studies in Second Language Acquisition, 35, 483-517. https://doi.org/ 10.1017/S0272263113000119

Godfroid, A et al. (2018). Incidental vocabulary learning in a natural reading context: an eye-tracking study. Bilingualism: Language and Cognition, 21(3), 563-584. https://doi.org/ 10.1017/S1366728917000219

Guo, Yali. (2010). L2 Vocabulary acquisition through reading -incidental learning and intentional learning. Chinese Journal of Applied Linguistis, 33, 74-93.

Hu, H. M. (2013). The effects of word frequency and contextual types on vocabulary acquisition from extensive reading: A case study. Journal of Language Teaching and Research, 4(3), 487-495. https://doi.org/ 10.4304/jltr.4.3.487-495

Huang, S., Willson, V. \& Eslami Z. (2012). The effects of task involvement load on L2 incidental vocabulary learning: A meta-analytic study. Modern Language Journal, 96(4), 544-557. https://doi.org/10.1111/j.15404781.2012.01394.x

Krashen, S. D. (1989). We acquire vocabulary and spelling by reading: Additional evidence for the Input Hypothesis. Modern Language Journal, 73, 440-464. https://doi.org/10.1111/j.1540-4781.1989.tb05325.x

Kweon Soo-Ok \& Kim Hae-Ri. (2008). Beyond raw frequency, Incidental vocabulary acquisition in extensive reading. Reading in a Foreign Language, 20(2), 191-225.

Laufer, B. (2001). Reading, word-focused activities and incidental vocabulary acquisition in a second language. Prospect, 16(3), 44-54.

Laufer, B. (2003). Vocabulary acquisition in a second language: Do learners really acquire most vocabulary by reading? Some empirical evidence. Canadian Modern Language Review, 59, 567-87. https://doi.org/10. 3138/cmlr.59.4.567

Lee, S., \& Pulido, D. (2017). The impact of topic interest, L2 proficiency, and gender on EFL incidental vocabulary acquisition through reading. Language Teaching Research, 21(1), 118-135. https://doi.org/10. $1177 / 1362168816637381$

Lewis, M. (2000). Teaching collocation. Hove, UK: Language Teaching Publications.

Lin, G. (2018). Effects of the initial test interval and feedback timing on L2 vocabulary retention. The Language Learning Journal. https://doi.org/10.1080/09571736.2018.1551416

Mahdavy, B. (2011). The role of topic familiarity and rhetorical organization of texts in L2 incidental vocabulary acquisition. Procedia-Social and Behavioral Sciences, 29, 208-217. https://doi.org/10.1016/j.sbspro.2011. 11.226

Malone, J. (2018). Incidental vocabulary learning in SLA, effects of frequency, aural enhancement, and working memory. Studies in Second Language Acquisition, 40(3), 651-675. https://doi.org/10.1017/ S0272263117000341

Mohamed, A. (2018). Exposure frequency in L2 reading: An eye-movement perspective of incidental vocabulary learning. Studies in Second Language Acquisition, 40(2), 269-293. https://doi.org/10.1017/ S0272263117000092

Nagy, W. E., Anderson, R. C., \& Herman, P. A. (1987). Learning word meanings from context during normal reading. American Educational Research Journal, 24, 237-270. https://doi.org/10.3102/000283120 24002237

Nation, I. S. P. (2001). Learning vocabulary in another language. Cambridge: Cambridge University Press. https://doi.org/10.1017/CBO9781139524759

Papi, M. (2018). Motivation as quality, regulatory fit effects on incidental vocabulary learning. Studies in Second Language Acquisition, 40(4), 707-730. https://doi.org/10.1017/S027226311700033X 
Pellicer-Sánchez, A. (2015). Incidental L2 vocabulary acquisition from and while reading. Studies in Second Language Acquisition, 1-34. https://doi.org/10.1017/S0272263115000224

Peters, E., Hulstijn, J. H., Sercu, L., \& Lutjeharms, M. (2009). Learning L2 German vocabulary through reading:The effect of three enhancement techniques compared. Language learning, 59, 113-51. https://doi.org/10.1111/j.1467-9922.2009.00502.x

Pulido, D. (2007). The relationship between text comprehension and second language incidental vocabulary acquisition: A matter of topic familiarity? Language Learning, 57(1), 155-199. https://doi.org/10.1111/ j.1467-9922.2007.00415.x

Reynolds, B. L. (2016). The effects of target word properties on the incidental acquisition of vocabulary through reading. TESL-EJ, 20(3), 1-31. https://doi.org/

Schmitt, N. (2008). Review article: Instructed second language vocabulary learning. Language Teaching Research, 12, 329-363. https://doi.org/10.1177/1362168808089921

Schmitt, N., \& Zimmerman, C. B. (2002). Derivative words forms: What do learners know? TESOL Quarterly, $36(2), 145-171$. https://doi.org/10.2307/3588328

Sun, C. H. (2017). The value of picture-book reading-based collaborative output activities for vocabulary retention. Language Teaching Research, 21(1), 96-117. https://doi.org/ 10.1177/1362168816655364

Tekmen, E. A. F., \& Daloğlu, A. (2006). An investigation of incidental vocabulary acquisition in relation to learner proficiency level and word frequency. Foreign Language Annals, 39(2), 220-243. https://doi.org/10.1111/j.1944-9720.2006.tb02263.x

Vidal, K. (2003). Academic listening: A source of vocabulary acquisition? Applied Linguistics, 24(1), 56-86. https://doi.org/10.1093/applin/24.1.56

Vidal, K. (2011). A Comparison of the Effects of Reading and Listening on Incidental Vocabulary. Language Learning, 61(1), 219-258. https://doi.org/ 10.1111/A.1467-9922.2010.00593.x

Webb, S. (2008). The effects of context on incidental vocabulary learning. Reading in a Foreign Language, 20(2), 232-245.

$\mathrm{Xu}, \mathrm{X}$. H. (2010). An empirical study on the effect of task on L2 incidental vocabulary acquisition through reading. Asian Social Science, 6(7), 126-131. https://doi.org/10.5539/ass.v6n7P126

Yoshii, M., \& Flaitz, J. (2002). Second language incidental vocabulary retention: The effect of text and picture annotation types. CALICO Journal, 20(1), 33-58. https://doi.org/10.2307/24149608

Zahar, R., Rick, C., \& Spada, N. (2001). Acquiring vocabulary through reading: effects of frequency and contextual richness. Canadian Modern Language Review, 57(4), 541-572. https://doi.org/10.3138/cmlr.57.4.541

\section{Copyrights}

Copyright for this article is retained by the author(s), with first publication rights granted to the journal.

This is an open-access article distributed under the terms and conditions of the Creative Commons Attribution license (http://creativecommons.org/licenses/by/4.0/). 